\title{
Intraoperative Consultation (Frozen Section) in the Diagnosis of Ovarian Tumour
}

\author{
${ }^{*}$ Ferdous $\mathrm{J}^{1}$, Chowdhury $\mathrm{S}^{2}$, Begum $\mathrm{F}^{3}$, Akhter $\mathrm{S}^{4}$, Khatun $\mathrm{S}^{5}$, Faika $\mathrm{J}^{6}$
}

\begin{abstract}
Ovarian cancer is a devastating disease preoperative evaluation of the patients with an ovarian tumour is difficult. So frozen section biopsy of ovarian tumour is important to determine the extent of surgery. This retrospective cross-sectional study was carried out in the Department of Gynaecological Oncology, Bangabandhu Sheikh Mujib Medical University from August 2016 to July 2017 to determine the validity of frozen section biopsy in the diagnosis of ovarian tumour. Fifty cases of ovarian tumour underwent frozen section biopsy were included by purposive sampling. Histopathological finding was taken as the gold standard. Data was analyzed by SPSS version 16. The sensitivity of frozen section in the diagnosis of benign, borderline and malignant were $100 \%, 100 \%$ and $97.67 \%$ respectively as well as the specificities were 100\%, 97.96\% and 100\% respectively. Similarly the accuracy, PPV, NPV for the benign, borderline and malignant ovarian tumour were also high except the borderline tumour which had low PPV.
\end{abstract}

Keywords: Ovarian tumour, intraoperative consultation, frozen section.

\section{INTRODUCTION}

Ovarian cancer is the $7^{\text {th }}$ most common cancer among female globally ${ }^{1}$. It is a devastating disease as it is often diagnosed late, hence related to poor diagnosis and

1. *Professor Jannatul Ferdous, Department of Gynaecological Oncology, Bangabandhu Sheikh Mujib Medical University (BSMMU). E-mail:jannatulferdous71@yahoo.com

2. Dr. Shiuly Chowdhury, Department of Obs \& Gynae, BSMMU

3. Ferdousy Begum, Associate Professor, Department of Pathology, BSMMU

4. Dr. Shabnam Akhter, Associate Professor, Department of Pathology, BSMMU

5. Professor Sabera Khatun, Ex-Chairman, Department of Gynaecological Oncology, BSMMU

6. Dr. Jakanta Faika, Phase-B Resident, Department of Gynaecological Oncology, BSMMU

* For correspondence survival. ${ }^{2}$ Among the cancers of the female genital tract, ovarian cancer is the second leading cause of death world wide. ${ }^{3}$ Patients with ovarian masses are presenting a persistent agonizing problem due to their inconsistent clinical presentation, difficulties in early diagnosis and wide variations in histological architecture. Preoperative evaluation of the patients with an ovarian tumour is usually made by imaging and estimation of the serum tumour marker. Since these methods have limited value for the recognition of ovarian cancer. The diagnosis of ovarian cancer and the extent of surgery are usually determined by frozen section examination during the surgical procedure ${ }^{4}$. So, the accuracy of frozen section biopsy of ovarian tumour is important as it will influence the line of management, such as conservative versus radical surgery. Conservation of the uterus and the other ovary can be vital to the young patients to whom fertility is an important concern. ${ }^{5}$ In the literature, the reported frozen section utilization ratios for ovarian lesions range from $7.4 \%$ to $47 \%{ }^{6}$

Frozen section diagnosis should not be seen merely as a microscopic examination of the tissue. Rather, it is an intraoperative consultation method in which other diagnostic tests such as gross examination, touch imprints are used in combination. Hence, some have preferred that the term "frozen section examination" be eliminated in favor of the term "intraoperative consultation" Careful gross examination of the specimen is of utmost importance for both correct sampling and arriving at the correct diagnosis.

This retrospective study was performed to determine the validity of frozen section biopsy in the diagnosis of ovarian tumour in the Department of Gynaecological Oncology at Bangabandhu Sheikh Mujib Medical University.

\section{MATERIALS AND METHODS}

This retrospective cross-sectional study was carried out in the Department of Gynaecological Oncology, Bangabandhu Sheikh Mujib Medical University from August 2016 to July 2017. Fifty cases of ovarian tumour were evaluated according to frozen and paraffin section diagnosis in the Department of Pathology, BSMMU during this period. So, these 50 cases were included in this study by purposive sampling by reviewing the hospital record form. Regarding the ethical implications, as this was a retrospective study using the hospital record form, so 
permission was taken from the Unit head of the then Gynaecological Oncology division of BSMMU. The demographic features of the study population, standard biochemical tests and the reports were recorded in a pre-designed data collection sheet.

\section{Preparation of frozen section:}

The frozen and paraffin section diagnosis were reported by two pathologists of the Department of Pathology, BSMMU experienced in gynaecological pathology. Following gross inspection, representative samples of suspicious areas with emphasis on solid, papillary or thickend regions was collected for frozen section evaluation. During this procedure portions of resected specimens were taken in the cryostat machine. After quick freezing (at -20 to $-25^{\circ} \mathrm{C}$ ), these blocks was sectioned at thickness of 5 micrometer in the cryostat. Frozen sections were then quickly immersed in Koplin's jar containing 95\% alcohol for 20 seconds. The slides were then stained with rapid Haematoxyline and eosin staining method. After staining cover slips were mounted over the sections with Di-N-butyle Phthalate in Xylene (DPX). Frozen slides were and results were documented as negative for malignancy or positive for malignancy or suspicious.

Histopathological finding was taken as the gold standard. The frozen section diagnosis was compared with the final paraffin section diagnosis in terms of whether it was a non neoplastic lesion or a benign, borderline, and malignant tumour. Data was analyzed by SPSS version 16 . Quantitative observations were indicated by frequencies and percentages.. For the validity of study outcome, sensitivity, specificity, accuracy, positive predictive value (PPV) and negative predictive value (NPV) of frozen section biopsy in the evaluation of ovarian masses was calculated. The results were presented in tables

\section{RESULTS}

This retrospective cross sectional study was carried out with an aim to find out the sensitivity, specificity, accuracy, positive predictive value (PPV) and negative predictive value (NPV) for diagnosis of ovarian tumour evaluated by frozen section biopsy.

A total of 50 cases with ovarian tumour who underwent laparotomy in the Gynaecological Oncology Division of Bangabandhu Sheikh Mujib Medical University, from August 2016 to July 2017 were included in this study. The mean age of the patients was $47.54 \pm 12.49$ years. Clinically $78 \%$ patients were suspected having malignant ovarian tumor. Frozen section biopsy revealed that $12 \%$ cases were benign, $4 \%$ were borderline and $84 \%$ cases were malignant. Histopathological examination revealed that $12 \%$ cases were benign, $2 \%$ cases were borderline and $86 \%$ cases were malignant. The sensitivity of frozen section in the diagnosis of benign, borderline and malignant were $100 \%, 100 \%$ and $97.67 \%$ respectively as well as the specificities were $100 \%, 97.96 \%$ and $100 \%$ respectively. Similarly the accuracy, positive predictive value (PPV), negative predictive value (NPV) for the benign, borderline and malignant ovarian tumour were also high except the borderline tumour which had low PPV.

Table - I shows the age distribution of the study subjects, it was observed that $42 \%$ of patients belonged to less than 50 years age group. The mean age of the patients was $47.54 \pm$ 12.49 years with the age range 18-72 years.

Table I: Age distribution of the study patient $(n=50)$

\begin{tabular}{|l|c|c|}
\hline Age (in years) & Number of Patients & Percent \\
\hline$<20$ & 2 & 4.0 \\
\hline $20-30$ & 4 & 8.0 \\
\hline $31-40$ & 10 & 20.0 \\
\hline $41-50$ & 13 & 26.0 \\
\hline$>50$ & 21 & 42.0 \\
\hline Total & 50 & 100.0 \\
\hline
\end{tabular}

Table - II shows the clinical features of the study subjects, it was observed that majority $39(78.0 \%)$ of the study subjects were diagnosed as malignant ovarian tumour, $6(12 \%)$ as tubo ovarian cyst/mass and $5(10.0 \%)$ were as benign ovarian tumour.

\section{Table II: Distribution of the patients according to} clinical feature $(n=50)$ :

\begin{tabular}{|l|c|c|}
\hline Clinical feature & N. of patients & Percent \\
\hline Tubo-Ovarian mass & 6 & 12.0 \\
\hline Benign Ovarian Tumour & 5 & 10.0 \\
\hline Malignant Ovarian Tumour & 39 & 78.0 \\
\hline Total & 50 & 100.0 \\
\hline
\end{tabular}

Table-III shows the serum CA-125 level among the study subjects, it was observed that majority $(86.0 \%)$ had raised CA-125 (>35 IU/ml) \& it was normal in 7(14.0\%) cases.

Table III: Distribution of the patients according to CA -125 ( $n=50)$.

\begin{tabular}{|l|c|c|}
\hline Level of CA - 125 & Number of patients & Percent \\
\hline$\leq 35$ & 7 & 14.0 \\
\hline$>35$ & 43 & 86.0 \\
\hline Total & 50 & 100.0 \\
\hline
\end{tabular}


Table-IV shows the Frozen section of the ovarian tumour revealed malignant in $42(84.0 \%)$ cases, benign in $6(12.0 \%)$ cases and borderline in $2(4 \%)$ cases.

Table IV: Distribution of the patients according to diagnosis of ovarian mass by frozen section

\begin{tabular}{|l|c|c|}
\hline $\begin{array}{l}\text { Ovarian mass by } \\
\text { frozen section }\end{array}$ & No. of patients & Percent \\
\hline Benign & 6 & 12.0 \\
\hline Borderline & 2 & 4.0 \\
\hline Malignant & 42 & 84.0 \\
\hline Total & 50 & 100.0 \\
\hline
\end{tabular}

Table $\mathrm{V}$ shows the Final histopathological diagnosis of the ovarian tumour revealed, $43(86 \%)$ cases were malignant, $6(12 \%)$ as benign and $1(2 \%)$ as borderline ovarian tumour.

\section{Table V: Distribution of the patients according to histopathological diagnosis}

\begin{tabular}{|l|c|c|}
\hline Histopathological diagnosis & No. of patient & Percent \\
\hline Benign & 6 & 12.0 \\
\hline Borderline & 1 & 2.0 \\
\hline Malignant & 43 & 86.0 \\
\hline Total & 50 & 100.0 \\
\hline
\end{tabular}

Table VI : A total of 6 cases were evaluated as benign and all of them revealed as benign by histopathology as well, 2 cases were borderline on frozen biopsy but histopathology confirmed 1 case as borderline, and 42 cases revealed as benign in frozen but final histopathology confirmed as malignant in 43 cases. One case of borderline tumour was over diagnosed and one case of malignant was missed by frozen section biopsy.

Table VI: Comparison between histopathological diagnosis and frozen section biopsy report of ovarian masses

\begin{tabular}{|l|c|c|c|c|}
\hline Variable & \multicolumn{3}{|c|}{$\begin{array}{c}\text { Histopathological } \\
\text { diagnosis(n=50) }\end{array}$} & $\begin{array}{c}\text { Total } \\
(\mathrm{n}=50)\end{array}$ \\
\hline $\begin{array}{l}\text { Frozen Section } \\
(\mathrm{n}=50)\end{array}$ & Benign & Borderline & Malignant & \\
\hline Benign $(\mathrm{n}=6)$ & 6 & 0 & 0 & 6 \\
\hline Borderline $(\mathrm{n}=2)$ & 0 & 1 & 1 & 2 \\
\hline Malignant $(\mathrm{n}=42)$ & 0 & 0 & 42 & 42 \\
\hline Total & 6 & 1 & 43 & 50 \\
\hline
\end{tabular}

Table VII : The sensitivity of frozen section diagnosis for benign, borderline and malignant ovarian tumour were $100 \%, 100 \%$ and $96.67 \%$ respectively as well as the specificities were $100 \%, 97.96 \%$ and $100 \%$ respectively. The accuracy was $100 \%$ for benign tumours and , $98 \%$ for both borderline \& malignant tumours of ovary. PPV and, NPV for the benign tumours was $100 \%$; PPV \& NPV for the borderline ovarian tumour were $50 \%$ \& $100 \%$ respectively and for the malignant ovarian tumours were $100 \% \& 87.5 \%$ respectively.

Table VII: Sensitivity, specificity, accuracy, positive and negative predictive values of frozen section in the diagnosis of ovarian tumour.

\begin{tabular}{|l|c|c|c|c|c|}
\hline \multirow{3}{*}{ Benign } & $\begin{array}{c}\text { Sensitivity } \\
(95 \% \mathrm{CI})\end{array}$ & $\begin{array}{c}\text { Specificity } \\
(95 \% \mathrm{CI})\end{array}$ & $\begin{array}{c}\text { Accuracy } \\
(95 \% \mathrm{CI})\end{array}$ & PPV & NPV \\
\hline Borderline & $\begin{array}{c}100 \% \\
(54.07-100 \%)\end{array}$ & $\begin{array}{c}100 \% \\
(91.96-100 \%)\end{array}$ & $\begin{array}{c}100 \% \\
(92.89 \%-100 \%)\end{array}$ & 100 & 100 \\
\hline Malignant & $\begin{array}{c}(2.50 \% \% \\
(87.67 \%\end{array}$ & $\begin{array}{c}97.96 \% \\
(89.15 \%-99.95 \%)\end{array}$ & $\begin{array}{c}98 \% \\
(89.35 \%-99.95 \%)\end{array}$ & 50 & 100 \\
\hline
\end{tabular}




\section{DISCUSSION}

Frozen section diagnosis is an important and reliable tool in the clinical management of patients with ovarian tumours. However, little information has been published concerning the utilization ratio of frozen section in ovarian tumour. In the literature, the reported frozen section utilization ratios for ovarian lesions range from $7.4 \%$ to $47 \% .6,8,9$ Since most of the patients with ovarian tumour undergo surgery without a definite tissue diagnosis, the diagnosis and the course of the surgery are usually determined by performing frozen section. Benign lesions are managed conservatively, borderline and malignant ovarian tumours are managed by definitive surgery, omental biopsy or omentectomy and comprehensive surgical staging or debulking surgery depending on the stage of the disease. ${ }^{10,11}$ So, accurate intraoperative diagnosis is imperative.

Many studies have assessed the accuracy of frozen section in ovarian tumours. In the present study, 6 benign ovarian tumours were diagnosed intraoperatively as benign by frozen section and no false positive cases evaluated by histopathology. This result showed that there is agreement with frozen section and histopathology in the diagnosis of benign ovarian tumour. But 1 out of 2 cases of borderline ovarian tumours there was disagreement in the diagnosis and 1 out of 43 cases of malignant ovarian tumours was misdiagnosed as borderline. In that casee, the frozen section diagnosis of 1 borderline tumour (mucinous borderline tumour) turned out to be malignant on final histology and that was mucinous cystadenocarcinoma. Borderline ovarian epithelial tumours have always been a major cause of pitfall in frozen section diagnosis with less reliable results compared to benign and malignant tumours. $5,610,12,13,14$

Houck et al reviewed 140 borderline ovarian tumours which showed that in $60 \%$ of cases, frozen section diagnosis agreed with permanent diagnosis ${ }^{13}$. Over diagnosis was reported in $10.7 \%$ and $29.3 \%$ of cases were under diagnosed ${ }^{13}$. Other studies also report a less than $90 \%$ overall sensitivity for borderline tumours. ${ }^{10,11,12,14}$ In the literature, frozen section examination has a high accuracy rate in ovarian tumours, reported at greater than $90 \%{ }^{9,15-22}$.

In this present study, the accuracy was $100 \%, 98 \%$ and $98 \%$ for benign, borderline and malignant ovarian tumours respectively. The sensitivity rates for benign, borderline and malignant tumours were found as $100 \%$,
$100 \%$ and $97.67 \%$ respectively which correlate with the other series. ${ }^{9,17,19-21}$

In this study the positive predictive value of frozen section evaluation in the diagnosis of ovarian malignancies was $100 \%$. This finding is consistent with the other studies which reported positive predictive values of $99.1 \%$ to $100 \%$, making overtreatment an unlikely event $9,1518,23$

Several literatures have shown that the causes of discordance between frozen section and histology are due to sampling error, misinterpretation, lack of communication with the surgeons, and technical problems. ${ }^{17}$

At BSMMU during the intraoperative consultation, the pathologists are able to communicate with a responsible surgeon from the surgical team and also receive the clinical information and intraoperative findings which is also an important component during frozen section.

\section{CONCLUSION}

This study confirms that frozen section diagnosis is a reliable method in the intraoperative evaluation of ovarian tumour in our instituition. However, diagnostic problem can occur in borderline ovarian tumour during frozen section biopsy and the pathologists as well as the surgeons must be aware of the limitations of this procedure, and a good communication between pathologists and surgeons is required to obtain more accurate results.

\section{Limitations of the study}

The study population was selected from one selected hospital in Dhaka city with limited sample size, so that the results of the study may not be reflect the exact picture of the whole country.

\section{REFERENCES}

1. Bhatla N, Denny L. FIGO's updated Cancer Report 2018. Int J Gynecol Obstet 2018; 143(suppl.2):2-3.

2. American Cancer Society. Cancer facts and figures 2020.https://www.cancer.org/research/cancer-facts-st atistics/all-cancer-facts-figures/cancer-facts-figures-20 20.html.

3. Modugno F. Ovarian cancer and polymorphism in the Androgen and Progesterone receptor genes: A HUGE Review. Am J Epidemiol 2004; 159: 319- 335.

4. Lim FK, Yeoh CL, Chong SM, Arulkumaran S. Pre and intraoperative diagnosis of ovarian tumours: how accurate are we? Aust NZ J Obstet Gynaecol 1997; $37: 223-7$. 
5. Gol M, Baloglu A, Yigit S, Dogan M, Aydin C, Yensel $\mathrm{U}$. Accuracy of frozen section diagnosis in ovarian tumors: Is there a change in the course of time?. Int J Gynecol Cancer 2003; 13: 593-597.

6. Twaalfhoven FC, Peters AA, Trimbos JB, Hermans J, Fleuren GJ. The accuracy of frozen section diagnosis of ovarian tumors. Gynecol Oncol 1991; 41: 189-92.

7. Fechner RE. Frozen section (intraoperative consultation). Hum Pathol 1988; 19: 999-1000.

8. Maiman M, Selzer V, Boyee J. Laparoscopic excision of ovarian neoplasm subsequently found to be malignant. Obstet Gynecol 1991; 77: 563-5.

9. Puls L, Heidtman E, Hunter JE, Crane M, Stafford J. The accuracy of frozen section by tumor weight for ovarian epithelial neoplasms. Gynecol Oncol 1997; 67: 16-9.

10. Ilvan S, Ramazanoglu R, Akyildiz EU, Calay Z, Bese $\mathrm{T}$, Oruc N. The accuracy of frozen section (intraoperative consultation) in the diagnosis of ovarian masses. Gynecologic Oncology 2005; 97: 395-399.

11. Pinto PB, Andrade LA, Derchain SF. Accuracy of intraoperative frozen section diagnosis of ovarian tumors. Gynecol Oncol 2001; 81: 230-2.

12. Maheshwari A, Gupta S, Kane S, Kulkarni Y, Goyal BK, Tongaonkar HB. Accuracy of intraoperative frozen section in the diagnosis of ovarian neoplasm: experience at a tertiary oncology center. World J Surg Oncol 2006;4:12.

13. Houck K, Nikrui N, Duska L, Chang Y, Fuller AF, Bell D. et al. Borderline tumours of the ovary: correlation of frozen and permanent histopathological diagnosis. Obset Gynecol 2000;95(69):839-43.

14. Kim JH, Kim TJ, Park YG, Lee SH, Lee CW, Song MJ,et al. Clinical analysis of intra-operative frozen section proven borderline tumours of the ovary. J Gynecol Oncol 2009;20(3):176-80.
15. Obiakor I, Maiman M, Mittal K, Awobuluyi M, DiMaio T, Demopooulos R. The accuracy of frozen section in the diagnosis of ovarian neoplasms. Gynecol Oncol 1991; 43(1):61-3.

16. Tangjitgamol S, Jesadapatrakul S, Manusirivithaya S, Sheanakul C. Accuracy of frozen section in diagnosis of ovarian mass. Int J Gynecol Cancer 2004;14(2): 212-9.

17. Wang KG, Chen TC, Wang TY, Yang YC, Su TH. Accuracy of frozen section diagnosis in gynecology. Gynecol Oncol 1998; 70: 105-10.

18. Crum CP. 'The female genital tract' in Robbins and Cotran Pathologic Basis of Disease, 7th edition, Kumar V, Abbas AK, Fausto N (eds), Elsevier Saunders, Philadelphia 2004; pp. 1092-1117.

19. Mills SE, Carter D, Greenson JK, Oberman HA, Reuter V, Stoler MH. Sternberg's Diagnostic Surgical Pathology. 4th ed. Philadelphia: Williams \& Wilkins;2004.

20. Benedet JL, Bender H, Jones H, 3rd, Ngan HY, Pecorelli S. FIGO staging classifications and clinical practice guidelines in the management of gynecologic cancers. FIGO Committee on Gynecologic Oncology. Int J Gynaecol Obstet 2000;70(2):209-62.

21. Robinson WR, Curtin JP and Morrow CP. Operative staging and conservative surgery in the management of low malignant potential ovarian tumors. Int. J. Gynecol. Cancer 1992; 2: 113-118.

22. Kim K, Chung HF, Kim JW, Park NH, Song YS, Kang SB. Clinical impact of under-diagnosis by frozen section examination is minimal in borderline ovarian tumors. Eur J Surg Oncol 2009;35(9):969-73.

23. Brun JL, Cortez A, Rouzier R, Callard P, Bazot M, Uzan $S$, et al. Factors influencing the use and accuracy of frozen section diagnosis of epithelial ovarian tumors. Am J Obstet Gynecol 2008;199(3):244-7. 